the long outside splint and weights, varying from ten pounds to fourteen pounds, the average amount of shortening was more than an inch; in one case, it was two inches; in five, it was one and a half; in five, it was one; and in two only, was it less than an inch. No case is recorded in which there was no shortening. This exactly accords with eleven cases reported by Mr. Cooper Forster in the Gucy's Hospital Report for 1875. Out of seventeen also unselected cases, treated with the Hodgen's splint, the average amount of shortening was considerably less than half an inch. In two cases, it was one inch, and in all the rest it was less than an inch; six cases being returned without any shortening.

\section{HYDROBROMIC ACID.}

\section{By EDWARD WOAKES, M. D.,} Surgeon to the Throat Hospital.

THIs drug having established its claim to antagonise the ear-symptoms occasioned by large doses of quinine, there appears to be but one step between this fact and the inference that it should be equally efficacious in analogous states of the ear arising from other'causes. Viewing certain forms of tinnitus as possessing marked analogy to the condition induced by quinine-one, that is, of congested labyrinthine circulationI have prescribed certain remedies with a view to the relief of this most distressing symptom; amongst these codeia, with some advantage, but not in any degree comparable to the results attending the hydrobromic acid. It may be needless to remark that the cases should be selected with a view to their appositeness to the presumed physiological action of the drug; and the indication which should be regarded as most distinctly pointing in this direction is that the noises have more or less of a pulsating, or, as the patient will describe it, a "knocking" character. The existence of vertigo, if present, will rather confirm the indication for the exhibition of the acid. The subjoined cases are intended to illustrate these remarks, and are taken from a number of others under recent observation.

F. C., aged 24, was the subject of otorrhœa media, associated with tinnitus of a very distressing character. This latter symptom persisted long after the others had yielded to treatment. The patient, a fairly intelligent mechanic, described the noises as increased on lying down, when they became "like the knocking of his heart". He was ordered fifteen minims of hydrobromic acid in water every four hours. At his next visit, he stated that, after taking three doses, the noises had much diminished, an improvement which steadily continued, so that at the end of a week he considered himself well.

$\mathrm{J}$. T., a chorister, aged 33 , presented an acutely inflamed condition of the lining membrane of the middle ear, which projected through a large central perforation of the drum-head. The external meatus was red and tender in its deepest portion, and near the membrane were two granular polypoid growths. There was abundant otorrhœa of a very fotid description. After removal of the growths from the external canal, the subsidence of the inflammatory state of the tympanic cavity, together with the discharge, he still complained of pulsating noises in the head, increased by walking or stooping, headache and occasional giddiness. The hydrobromic acid was given, as in the previous case with an equally rapid disappearance of all the symptoms associated with the tinnitus.

Two points appear important to secure the success of the drug. I. The auditory apparatus must be clear of any well marked objective morbid process. 2. The tinnitus should present the characters of congested blood-supply, already alluded to. In mentioning the foregoing facts at a recent discussion at the Harveian Society, owing to the lateness of the hour, the distinctive indications for the successful administration of the drug were not insisted upon, an omission which, I trust, this communication will sufficiently rectify.

MARYLEBONE.-Dr. Whitmore states that in the quarter ending March 3 Ist there were registered 1,240 births and 920 deaths, which give an annual death-rate of 23 .10 per 1,000 , being 3.74 per 1,000 more than in the previous quarter. This excess was chiefly caused by an unusual mortality from pneumonia and bronchitis. There were four deaths of young children from small-pox, one of whom was successfully vaccinated seven days before the disease appeared. There were also nine deaths from this disease in the Metropolitan Asylum Hospitals. A meteorological summary is also given for the quarter, showing that the highest and lowest temperatures were observed in March, and that as much as 5.06 inches of rain were registered in January. The sanitary works carried out show reasonable activity for the time of year.

\section{OBSTETRIC MEMORANDA.}

\section{PUERPERAL ERYSIPELAS.}

Mr. ForD's Case of Erysipelas in connection with the Puerperal State reported in the JOURNAL of June 2nd, reminds me of a similar one which came under my care about a month ago. In my case, however, an altack of facial erysipelas came on three or four days after labour, and readily yielded in a few days to treatment by the internal use o! tincture of sesquichloride of iron and the external application of thin gruel; nor was there any interference with either lochial or lacteil secretion. Unlike Mr. Ford's patient, mine was in very indigent circumstances. J. B. WiLliams, M.R.C.S., L.S.A., Hull.

\section{MIDWIFERY-FORCEPS.}

THERE is no instrument used by the medical profession of which there are so many varieties as midwifery forceps. In the lists published by Maw, Son, and Thompson, and by Arnold and Son, there are forty-five. Each, no doubt, in the opinion of the inventor, has its peculiar advantages; but in all the long forceps there is a very serious defect : $i . e_{\text {. }}$ it is impossible to use traction with them in the axis of the inlet of the pelvis, without using undue pressure on the perineum or os pubis of the mother. To illustrate what I mean, let us bear in mind the direction of the pelvic axis. A line, carried from the umbilicus to the middle of the coccyx, gives the axis of the inlet; a line, drawn from the upper part of the sacrum to the centre of the outlet, gives its axis. Let us take it for granted that the child's head is at the inlet, and we want to deliver ; if we attempt it with straight forceps, we frind the thing impossible (unless the sacrum be very slightly curved anri the perineum short), because the instrument will occupy the axis of the outlet. With curved forceps, we may deliver-but how? The blades are in the axis of the inlet, the handles in the axis of the outlet, and, consequently, nearly all the force must be exerted against the os pubis. With these mechanical disadvantages, the pressure unavoidably employed is often sufficient to sacrifice the life of the child. It is said that, with "Tarnier's new forceps", or rather two forceps, the operator can always use traction in the axis of the pelvis, and I believe this to be the case; but the instrument is too complicated, and requires the use of both hands, one to each forceps. A far simpler instrument, about which I have been thinking for some time past, will do all that it is sairi to do. Let us take, for example, Knight's forceps (there is a picture of it in Maw and Son's illustrated list) ; it locks by a screw, the handles are of steel, with a blunt hook at the end of each. Now, let us bend the handles as much backwards as the blades are curved forwards, and let us fancy that this instrument is applied on the child's head, and that it is at the brim of the pelvis; we find that the blades are in the axis of the inlet, the perinæum resting on the depression at the lock, and the ends of the handles on a line with the axis of the inlet of the pelvis; consequently, traction made by them must be in that line. As the labour advances, by letting the handles of the instrument go forward, one must be in the axis of the pelvis all the time. This instrument is very simple, and will require very little force, because it can always be used in the right direction; the lock will act as free as straight forceps, because the curve of the handle corrects the curve of the blade.

$$
\text { David Christie, L.R.C.P.E., Carrigart, Co. Donegal. }
$$

\section{GLASS SPECULA.}

IT may not be known to all the readers of the JOUR.AL that glass specula, not quite of the same kind as those mentioned by Dr. Murphy, have been used for many years in Germany. In 1866, I purchased, in Berlin, a case containing four specula of various sizes packed inside each other, and made of opalescent glass, which is very tough, and bears boiling water without cracking. I have used these constantly in my practice, and prefer them to any of the others in common use.

Thomas Fairiank, M.D., Windsor.

I FULLY agree with Dr. Murphy as to the superiority of plain glass specula. I have tried them, and have proved them to possess all the advantages which he claims for them.

My reason for writing, however, is to point out that the toughened glass of which he and other correspondents are desirous of having them made has been known to "explode" suddenly and without any apparent cause. Should this occur during their introduction, or while in situ, it would be extremely awkward, if not absolutely dangerous.

H. F. C. E.AGLE. 